\title{
Meiobenthic colonisation of soft sediments in arctic glacial Kongsfjorden (Svalbard)
}

\author{
Gritta Veit-Köhler ${ }^{\mathrm{a}, *, 1}$, Jürgen Laudien ${ }^{\mathrm{b}, 1}$, Jan Knott ${ }^{\mathrm{a}}$, Jose Velez ${ }^{\mathrm{b}}$, Ricardo Sahade ${ }^{\mathrm{c}}$ \\ a Senckenberg Research Institute, DZMB, Südstrand 44, 26382 Wilhelmshaven, Germany \\ ${ }^{\mathrm{b}}$ Alfred-Wegener-Institute for Polar and Marine Research, P.O. Box 120161, 27515 Bremerhaven, Germany \\ c Universidad National de Córdoba, Av. Vélez Sársfield 299, 5000 Córdoba, Argentina
}

\section{A R T I C L E I N F O}

\section{Article history:}

Received 31 December 2006

Received in revised form 16 June 2008

Accepted 17 June 2008

\section{Keywords:}

Arctic shallow water

Artificial substrate

Copepoda

Long-term colonisation experiment

Meiofauna communities

Nematoda

Succession

\begin{abstract}
A B S T R A C T
An in situ experiment on metazoan meiofauna colonisation and succession was carried out at Brandal $\left(78^{\circ} 56.88^{\prime} \mathrm{N}, 11^{\circ} 51.63^{\prime} \mathrm{E}\right)$, situated in arctic glacial Kongsfjorden (Spitsbergen). 28 soft sediment containers were deployed at a depth of $20 \mathrm{~m}$ and sampled after a one-, two- and three-year immersion period. The main taxonomic groups, abundance of colonising meiofauna and sediment parameters are described and compared. Meiofauna communities at Brandal show the highest densities reported for inner Kongsfjorden to date. While the samples from the three experimental periods and the ambient sediments did not differ in total individual numbers, the treatments showed marked differences in community structure as ascertained by ANOSIM based on Bray Curtis and cosine similarity. An extended three-year period was required until the community stage comparable to ambient sediments was reached. This leads to the assumption that long recovery and colonisation times can be expected for polar shallow water meiofauna.
\end{abstract}

(c) 2008 Elsevier B.V. All rights reserved.

\section{Introduction}

Polar shallow water habitats are frequently affected by natural environmental disturbances. Besides gradients that form in the course of sedimentation and freshwater run-off from tidal glaciers, another factor that may cause serious disturbance of benthic communities is iceberg scouring. A number of specific conditions, such as latitude, depth, local current regimes, geography and site exposure, influence such impacts (Barnes, 1999; Conlan et al., 1998; Dayton, 1990; Dayton et al., 1994; Dowdeswell and Forsberg, 1992; Gutt et al., 1996; Gutt and Piepenburg, 2003; Kotwicki et al., 2004). Physical disturbances both on spatial and temporal scales are thus highly variable. Laudien et al. (2007) assume that for macrobenthic infaunal communities at Kongsfjorden iceberg scouring may be the main structuring force, capable of producing up to $5 \mathrm{~m}$ deep plough marks (pers. observ.; Barrie, 1980) in water depths down to $40 \mathrm{~m}$ (Dowdeswell and Forsberg, 1992). On the other hand, increasing temperatures due to global warming lead to enhanced glacial retreat, thus creating new, ice-free areas providing a pristine habitat for the settlement of benthic organisms (Cook et al., 2005). Knowledge of colonisation by meiobenthic assemblages is crucial for an understanding of early community development when new substrate becomes available.

As community development is an extended process in polar environments (Barnes, 1996), a study of the successive colonisation should cover several years of monitoring. Therefore, the results of in situ subtidal

\footnotetext{
* Corresponding author. Tel.: +49 44219475 102; fax: +49 44219475111. E-mail address: gveit-koehler@senckenberg.de (G. Veit-Köhler).

1 These authors contributed equally to this work.
}

soft-bottom meiofauna colonisation experiments and recovery studies carried out in temperate regions (Chandler and Fleeger, 1983 and references therein; Schratzberger et al., 2002) cannot be applied to polar environments. Recently Lee et al. (2001) described recolonisation by meiofauna after iceberg scouring at Signy Island (Antarctica). However, no information on the recovery dynamics is available from the Arctic as yet.

Artificial substrata have commonly been used in studies of settlement, recruitment, colonisation and community development (Rumohr and Arntz, 1982; Sarnthein and Richter, 1974; Stanwell-Smith and Barnes, 1997). While reducing substratum heterogeneity, these substrata facilitate replication that is essential for analyses of variation (e.g. between treatments). The provision of artificial soft-sediments in our study at Brandal, Kongsfjorden (Spitsbergen) allowed for the simulation of natural conditions found in newly exposed areas. We therefore assumed that the sediments used in the experiment should not be enriched with organic material as compared to surrounding pristine sediments.

The field experiment was aimed at investigating the long-term colonisation by meiofauna assemblages in an arctic environment in terms of higher taxa abundance over a three-year period to improve the scarce knowledge on long-term community recovery in polar regions.

\section{Material and methods}

\subsection{Study area}

An in situ colonisation experiment was carried out at Brandal $\left(78^{\circ} 56.88^{\prime} \mathrm{N}, 11^{\circ} 51.63^{\prime} \mathrm{E}\right.$, world geodetic system - WGS 84$)$, a site located in central glacial Kongsfjorden (west coast of Spitsbergen, Svalbard, 


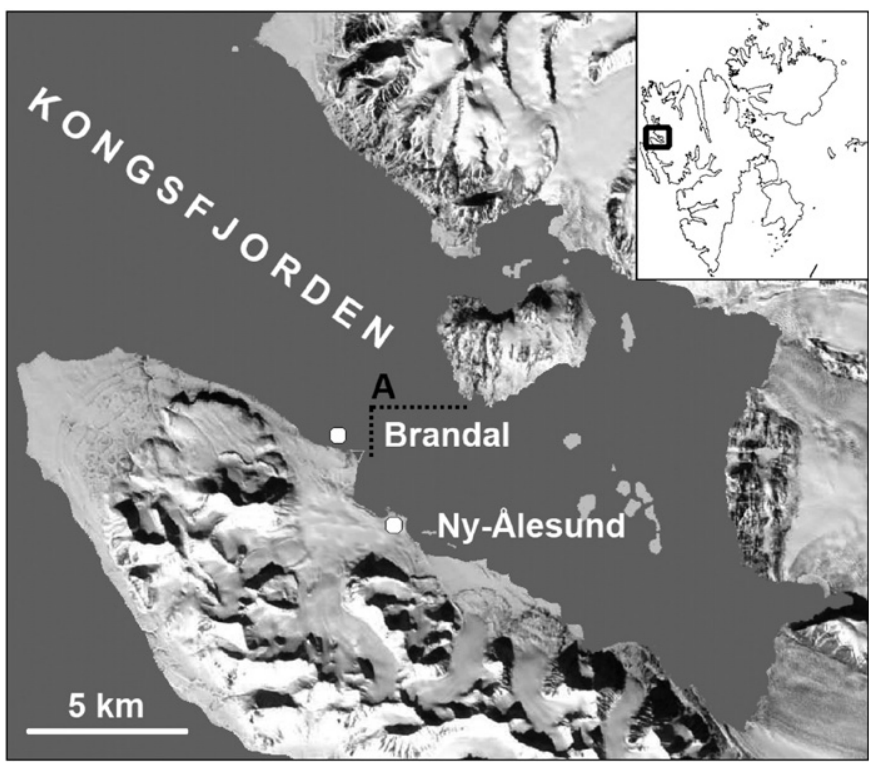

Fig. 1. Landsat TM image of Kongsfjorden at Spitsbergen, the largest island of the Svalbard archipelago (modified from Svendsen et al., 2002). The study site at Brandal, the village Ny-Ålesund and transect A of Dowdeswell and Forsberg (1992), where iceberg monitoring took place, are indicated.

Arctic). The study area is situated on the northeastern fringe of the Brøgger Peninsula, which forms the southern coast of Kongsfjorden (Fig. 1). The latter is $20 \mathrm{~km}$ long with a width varying from $4 \mathrm{~km}$ to $10 \mathrm{~km}$ at the mouth between Kvadehuken and Kapp Guissez. The maximum depth is nearly $350 \mathrm{~m}$ with an average depth of 200 to $300 \mathrm{~m}$. The fjord system is directly connected with the North Atlantic Ocean via the Kongsfjord-Renna trough (Bluhm et al., 2001; Jørgensen and Gulliksen, 2001; Svendsen et al., 2002).

Semidiurnal tides of the fjord system range between 1.5 and $2 \mathrm{~m}$ and only weak currents prevail. The mean sea surface temperature is just above $0{ }^{\circ} \mathrm{C}$, while maximal values may reach $6{ }^{\circ} \mathrm{C}$ in summer. The temperature at the $20 \mathrm{~m}$ isobath is $3.6{ }^{\circ} \mathrm{C}$ (Bluhm et al., 2001). During summer the 34 isohaline is located at a depth of $5 \mathrm{~m}$. During the winter Kongsfjorden is commonly covered with sea ice, while icebergs and growlers are present throughout the year (Dowdeswell and Forsberg, 1992). A comprehensive description of the physical environment can be found in Svendsen et al. (2002) and ecological information on Kongsfjorden is broadly compiled in Hop et al. (2002).

The widespread, apparently uniform soft bottom off Brandal (Fig. 1) declines gradually within the first $50 \mathrm{~m}$ from the coast, followed by a steeper slope. Sediments consist of a sand-clay mixture of quite homogeneous granulometric characteristics throughout the fjord (Wlodarska-Kowalczuk and Pearson, 2004; Kotwicki et al., 2004). For a nearby station ( $<1 \mathrm{~km}$ distance) M. Zajaczkowski (unpublished data, fide Wlodarska-Kowalczuk and Pearson, 2004) estimated a POC/ PON value of 7.6, indicating the presence of fresh detritus. Irregular boulders transported via ice are present providing settlement substrate for hard-bottom fauna and flora (e.g., Acrosiphonia aff. flagellata, Laminaria digitata and Phycodrys rubens) in the soft-bottom habitat (Whittington et al., 1997; Lippert et al., 2001).

\subsection{Experimental set-up}

Conical terracotta containers with an upper diameter of $43 \mathrm{~cm}$, a lower diameter of $40 \mathrm{~cm}$ and a height of $40 \mathrm{~cm}$ were installed by SCUBA divers at a depth of about $20 \mathrm{~m}$ in June 2002. Due to the adequate spacing between containers $(>1.5 \mathrm{~m})$, the replicates were considered to be independent (Conover, 1980). Round containers were chosen in order to keep edge effects equal (Foster, 1975). The bottoms of the 28 numbered containers were replaced by a glass-fibre reinforced plastic mesh ( $1 \mathrm{~mm}$ ) to allow vertical exchange processes. For the installation of the containers an open metal cylinder of the respective size was first pushed into the sediment in order to prevent sediment from sliding into the hole, which was then excavated with a small blade. The terracotta containers were placed in the pit and the cylinder was removed. A low $5 \mathrm{~cm}$ fringe of the containers remained above the surrounding sediment preventing it from entering into the experimental unit and avoiding a bias which would be caused by edges elevated higher over the benthic boundary layer. Since the walls of the containers provide a secondary hard substrate that may attract species not common on soft bottoms (Arntz, 1981), the containers were filled to the brim with pre-watered artificial sediment by the SCUBA diver. A 80:20 mixture of clean sand (fine and medium grain size) and clay (Calcium-Benthonit "Ibeco Agromont AWI", IKO Minerals GmbH, Marl, Germany) resembling the natural grain size distribution was used as it was difficult to sterilise large quantities of natural sediment and to remove the organic material. The remaining organic material could have caused unforeseeable effects on the settling fauna (Brunswig et al., 1976). A comparable artificial sediment has been successfully implemented in temperate waters (e.g. Sarnthein and Richter, 1974; Rumohr and Arntz, 1982). To avoid untimely initial colonisation while successively installing the containers, they were covered with plastic sheets until their simultaneous exposure (11 July 2002).

\subsection{Sampling and sample treatment}

In the following three years samples for meiofauna and sediment analyses were collected from randomly allotted containers (Table 1 ). Round plastic tube corers with a diameter of $4.5 \mathrm{~cm}$ (area: $15.90 \mathrm{~cm}^{2}$ ) were used to take one sample for meiofauna (in order to guarantee true replicates) and two to three samples for sediment analyses per container. Because the same experimental set-up was used for sampling macrofauna as well, the tube corers were not placed centrally in the containers. Nevertheless, a distance of at least $5 \mathrm{~cm}$ to the rim of the containers was always maintained. The uppermost $3 \mathrm{~cm}$ of the substrate provided were sampled.

For meiofauna analyses the sediment was preserved in a boraxbuffered formaldehyde-seawater solution to a final concentration of $4 \%$. The samples for sediment analyses were stored at $-80{ }^{\circ} \mathrm{C}$.

After each sampling, the remaining substrate in the corresponding container was completely removed by a SCUBA diver and replaced by fresh artificial sediment in order to start a new exposure series. Differences in the first-year primary succession between 2003 and 2004 were able to be tested by means of this procedure (Table 1 ). For comparison with the natural situation 5 sediment cores were taken outside the containers in 2005.

The fixed meiofauna samples were washed with tap water through a $40 \mu \mathrm{m}$ mesh sieve. Meiofauna and organic material were extracted from remaining sand particles by centrifugation with a colloidal silica polymer (H. C. Stark, Levasil 200/40\%, $\rho=1.17$ ) as the flotation medium and kaolin to cover heavier particles (McIntyre and Warwick, 1984). Centrifugation was repeated three times at $4000 \mathrm{rpm}$ for five minutes respectively. After each centrifugation the floating matter was decanted and rinsed with tap water. The supernatant containing the meiobenthic organisms was thereafter stained with Rose Bengal before manually sorting to a higher taxon level using a Leica MZ 12.5 stereo microscope. While specimens of most groups were stored in $70 \%$ ethanol, copepods were subsequently transferred to glycerine. Nematodes and nauplii were quantified as well but were left in the remaining sample. The

Table 1

Meiofauna samples from soft sediment containers at Brandal, Kongsfjorden: sampling date and number of replicates for different treatments and ambient samples

\begin{tabular}{lll}
\hline Treatment & No. of replicates & Date \\
\hline one-year exposure & 2 & $18 . / 19.06 .2003$ \\
& 3 & $27 . / 30 . / 31.08 .2004$ \\
two-year exposure & 3 & $01 . / 02 . / 03.09 .2004$ \\
three-year exposure & 3 & $02 . / 06 . / 07.09 .2005$ \\
ambient & 5 & 14.10 .2005 \\
\hline
\end{tabular}


Table 2

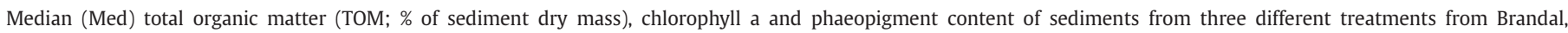
Kongsfjorden, Spitsbergen (minima (Min) and maxima (Max) included)

\begin{tabular}{|c|c|c|c|c|c|c|c|c|c|}
\hline \multirow{2}{*}{$\frac{\text { Exposure }}{\text { Sediment parameters }}$} & \multicolumn{3}{|c|}{ 1-year } & \multicolumn{3}{|c|}{ 2-year } & \multicolumn{3}{|c|}{ 3-year } \\
\hline & Med & Min & Max & Med & Min & Max & Med & Min & Max \\
\hline TOM [\% dm] & 2.034 & 1.496 & 2.592 & 1.895 & 1.603 & 2.721 & 3.069 & 2.539 & 3.189 \\
\hline Chlorophyll a [ $\mu \mathrm{g} \mathrm{mg}^{-1}$ ] & 0.161 & 0.144 & 0.266 & 0.223 & 0.168 & 0.318 & 0.239 & 0.226 & 0.287 \\
\hline Phaeopigments [ $\mu \mathrm{g} \mathrm{mg}^{-1}$ ] & 0.101 & 0.068 & 0.390 & 0.159 & 0.063 & 0.210 & 0.400 & 0.288 & 0.409 \\
\hline
\end{tabular}

All data from experimental units sampled in 2004 and 2005.

Table 3

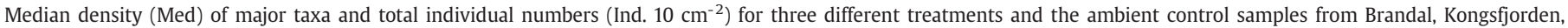
Spitsbergen (minima (Min) and maxima (Max) included)

\begin{tabular}{|c|c|c|c|c|c|c|c|c|c|c|c|c|}
\hline \multirow{2}{*}{$\frac{\text { Exposure }}{\text { Individuals }\left[10 \mathrm{~cm}^{-2}\right]}$} & \multicolumn{3}{|l|}{ 1-year } & \multicolumn{3}{|l|}{ 2-year } & \multicolumn{3}{|l|}{ 3-year } & \multicolumn{3}{|c|}{ ambient } \\
\hline & Med & Min & Max & Med & Min & Max & Med & Min & Max & Med & Min & Max \\
\hline Nematoda & 693.7 & 277.4 & 869.8 & 550.3 & 386.8 & 588.1 & 991.2 & 675.5 & 2087.4 & 1325.8 & 539.6 & 2158.5 \\
\hline Copepoda & 477.4 & 244.7 & 556.6 & 431.4 & 341.5 & 544 & 287.4 & 234.6 & 298.7 & 120.8 & 31.4 & 184.3 \\
\hline Copepod nauplii & 291.8 & 73.6 & 976.7 & 192.5 & 157.2 & 199.4 & 83.0 & 79.2 & 89.9 & 87.4 & 31.4 & 106.3 \\
\hline Annelida & 77.4 & 35.8 & 214.5 & 38.4 & 28.9 & 45.3 & 25.8 & 2.5 & 44.0 & 25.2 & 9.4 & 43.4 \\
\hline Halacarida & 11.9 & 5.7 & 49.1 & 13.8 & 9.4 & 23.3 & 3.8 & 3.1 & 3.8 & 3.8 & 1.3 & 12.6 \\
\hline Cumacea & 0.6 & 0 & 17.6 & 0 & 0 & 3.1 & 0.6 & 0 & 2.5 & 1.9 & 0 & 3.1 \\
\hline Bivalvia & 9.4 & 3.1 & 23.9 & 11.9 & 2.5 & 11.9 & 23.3 & 17.0 & 29.6 & 21.4 & 6.9 & 92.5 \\
\hline Amphipoda & 0.6 & 0 & 0.6 & 0 & 0 & 0 & 0 & 0 & 1.3 & 0.6 & 0 & 3.1 \\
\hline Loricifera & 0 & 0 & 1.3 & 0 & 0 & 0 & 0 & 0 & 0 & 0 & 0 & 0 \\
\hline Ostracoda & 6.9 & 1.9 & 12.6 & 1.9 & 1.9 & 3.1 & 2.5 & 1.9 & 6.9 & 2.5 & 1.3 & 6.3 \\
\hline Rotifera & 0 & 0 & 0.6 & 0 & 0 & 0 & 0 & 0 & 0 & 0.6 & 0.6 & 1.9 \\
\hline Tardigrada & 0 & 0 & 0 & 0 & 0 & 0 & 0 & 0 & 0 & 0 & 0 & 1.3 \\
\hline Priapulida & 3.8 & 1.3 & 27.7 & 6.9 & 5 & 6.9 & 0.6 & 0.6 & 5.0 & 1.3 & 0 & 5.7 \\
\hline Indet. & 3.8 & 0 & 48.4 & 0 & 0 & 15.1 & 0 & 0 & 0 & 0 & 0 & 5 \\
\hline Total individuals & 1576.7 & 764.2 & 2544 & 1220.8 & 1081.8 & 1318.2 & 1383 & 1088.1 & 2530.8 & 1613.2 & 645.9 & 2452.8 \\
\hline
\end{tabular}

individual numbers were counted and abundance values taken for further analyses and interpretation.

The frozen sediment samples were sliced $(0-1 \mathrm{~cm}, 1-2 \mathrm{~cm}, 2-3 \mathrm{~cm})$ and dried $\left(50{ }^{\circ} \mathrm{C}\right.$ until constant weight). The slices were analysed as to their content of organic material (combustion in a muffle furnace, $500{ }^{\circ} \mathrm{C}$ for $7 \mathrm{~h}$ ) and chloroplastic pigments (fluorometric determination after acetone extraction, Turner Fluorometer TD 700). The results for the first centimetre of the sediment were used for data analysis.

\subsection{Data analysis}

The data were not distributed normally, therefore no arithmetic means and standard deviations could be calculated for the different treatments. If outliers are presumed and in the event of skewed distributions, these values are replaced by the median and the median deviation (Sachs, 1993). In this case we added minima and maxima to the median values in order to demonstrate the distribution ranges of our meiofauna and environmental data.

Non-parametric Kruskal-Wallis one-way analysis by rank was applied to individual numbers and dominance D-values in order to test whether there were significant differences between the samples of the four groups (one-year, two-year, three-year and ambient sediments).

Multivariate meiofauna community analyses were carried out on square root transformed abundance data of the higher taxa recorded using the PRIMER v6 package (Clarke and Gorley, 2006) and the Paleontological Statistics Software Package PAST (Hammer et al., 2001).

Bray-Curtis and cosine similarity analyses were conducted for the square root transformed abundance data and visualised with the aid of non-metric multi-dimensional scaling MDS. The cosine similarity is a more "qualitative" measure as compared to the Bray-Curtis similarity, which discriminates more "quantitatively" between samples (Pfeifer et al., 1998). Overall, the cosine similarity reveals the structural properties of communities more than the Bray-Curtis similarity, which has the major drawback that it separates "similar" samples if the difference is mainly due to multiples in abundance (Pfeifer et al., 1998). For this reason we selected the cosine similarity as a counterpart to the widely used BrayCurtis similarity for our analyses.
Different factors (i.e. exposure time, sampling year) were applied for the analyses of similarities ANOSIM (one-way analysis) of the outcomes of both similarity indices in order to have a control tool for unexpected events that might occur in one year but not in the following. Thus differences could be detected independently from the starting year of the experiment.

For the interpretation of the relation of meiofauna with sediment factors a canonical correspondence analysis (CCA) was chosen, as this analysis enables comparison of animal data and environmental data in the same plot. CCA was carried out according to Ter Braak (1986) using the statistical package MVSP 3.1. No data transformations were carried out because every transformation bears the risk of bias.

\section{Results}

\subsection{Sediment parameters}

Sediment factors differed slightly between the three experimental periods (Table 2). The given minima and maxima indicate a high

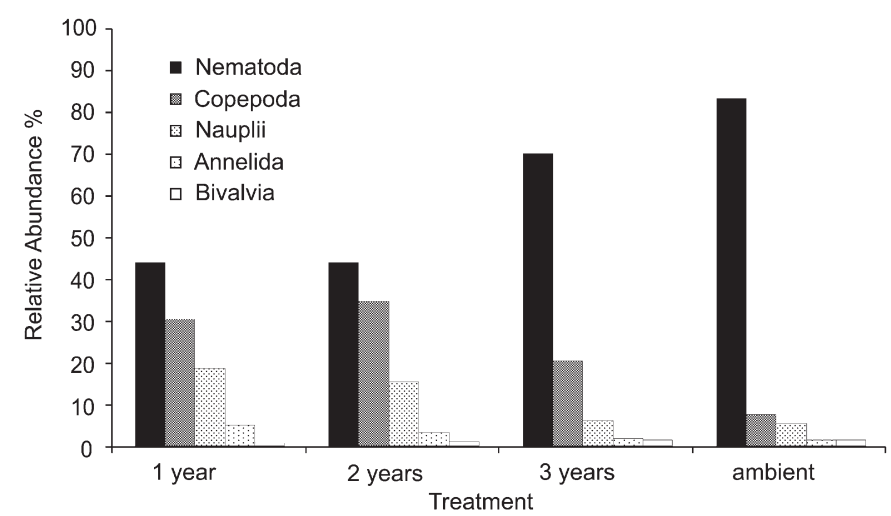

Fig. 2. Relative median abundances of meiofauna higher taxa and nauplii from sediments exposed for one, two and three years as well as ambient sediments from a succession experiment at Brandal, Kongsfjorden. 
variability of total organic matter, chlorophyll a and phaeopigment contents. Nevertheless, increased organic matter and the accumulation of phaeopigments in the third year of sediment exposure showed that there were detectable changes in the food supply for meiofauna throughout the duration of the experiment.

\subsection{Meiofauna abundances}

Animals belonging to twelve higher taxa colonised the ambient sediment as well as the sediment provided independently of exposure time (Table 3; for complete original data set see: Veit-Köhler et al., 2006). Total meiofauna abundance varied only slightly between treatments (minimum in two-year exposure, median: 1220.8 ind. $/ 10 \mathrm{~cm}^{2}$; maximum in ambient samples, median: 1613.2 ind./10 $\mathrm{cm}^{2}$ ). This is confirmed by the non-parametric Kruskal-Wallis test by ranks, which did not show any significant differences in total individual numbers between the samples $(\mathrm{H}=1.735, \mathrm{p}=0.6291)$. The differences between the dominance $\mathrm{D}$ measures for the meiofauna higher taxa in the samples, on the other hand, are highly significant $(H=13.61$; $\mathrm{p}=0.003484$ ), thus emphasising a shift in taxon composition with exposure time.

Throughout the experimental time (Fig. 2) it became obvious that nematode abundances were clearly higher than those of the other meiofauna groups in the three-year and the ambient samples. They comprised $44 \%$ of the total individuals in the sediment exposed for one year, $44.1 \%$ and $69.9 \%$ in the sediments exposed for two and three years respectively and $83.3 \%$ in the ambient samples (Fig. 2). The numerical importance of copepods and their nauplii diminished with exposure time as well as the relative abundances of annelids. Only bivalves showed slightly increasing values. The rise in relative abundances
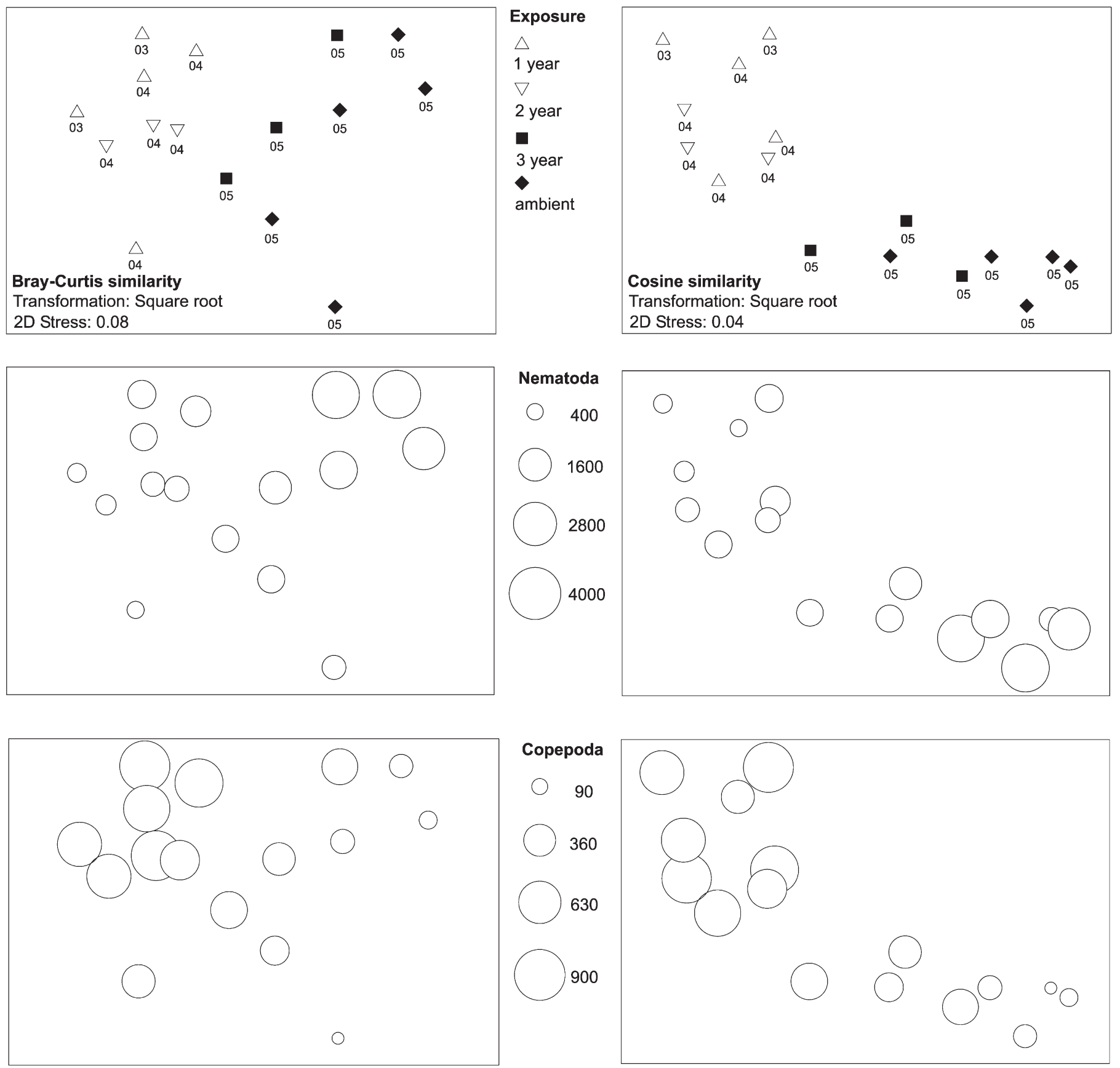

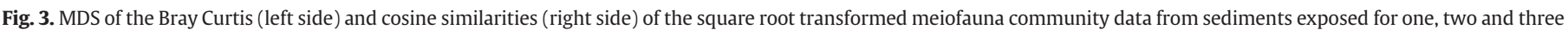
years as well as ambient sediment samples. Numbers close to station labels indicate sampling year. Nematode and copepod densities are shown as bubble plots. 
of nematodes was not only caused by the substantial increase in absolute nematode numbers, but also by the decreases in individual numbers of copepods, nauplii, and annelids.

Nematodes were numerically dominant in all but two samples. Their median abundances reached from 550.3 ind./10 $\mathrm{cm}^{2}$ (two-year exposure) to 991.2 ind. $/ 10 \mathrm{~cm}^{2}$ (three-year exposure) and ambient median values of 1325.8 ind./10 $\mathrm{cm}^{2}$. Copepods including adults and copepodids were numerically the second important group (one-year exposure, median: 477.4 ind./10 $\mathrm{cm}^{2}$; ambient, median: 120.8 ind./ $10 \mathrm{~cm}^{2}$ ) followed by copepod nauplii, which outnumbered copepods only in three samples. More than 99\% of the benthic copepods were Harpacticoida. The total percentage of all remaining taxa did not exceed 7.1\%; Annelida were still fairly abundant whereas Halacarida, Bivalvia, Ostracoda, Cumacea and Priapulida (larvae) showed lower individual numbers. Amphipoda, Loricifera, Rotifera, and Tardigrada were represented only rarely and in low numbers in our samples.

\subsection{Similarity analyses}

Numbers of nauplii may be more subject to seasonal changes than the rest of the copepods represented by copepodids and adults due to the shorter time span spent in this stage. As sampling dates inevitably varied throughout the years (Table 1), we removed nauplii from the data set before statistical tests were carried out. Especially the samples collected in June 2003 had very high naupliar abundances as compared to the samples of the other years taken later in the season.

The MDS resulting from the more "quantitative" Bray-Curtis and the more "qualitative" cosine similarity analyses are presented in Fig. 3. Although the Bray-Curtis similarity separates one- and two-year samples from three-year and ambient samples spatially, it is obvious that scatter within both groups is high (Fig. 3, graphs on the left). There are distances between ambient samples that are of a similar magnitude as distances between ambient and one-year samples. The same is true for the MDS of the cosine similarity, though the separation in this ordination plot is clearer and distances within the groups are smaller (Fig. 3, graphs on the right). Regarding the bubble plots for Nematoda and Copepoda of both MDS plots, the difference between the two similarity indices becomes obvious: the Bray-Curtis similarity only ordinates according to individual numbers, which is shown by the continuous change in bubble size over the array of the plot. The more variable distribution of bubbles of different sizes in the cosine similarity plots follows the characteristic of the index in grouping samples with comparable relative individual numbers rather than samples with similar absolute individual numbers.

As expected, ANOSIM of the Bray-Curtis and the cosine similarity led to different outcomes (Table 4). According to an analysis of the Bray-Curtis results, the global $\mathrm{R}$ value for the tests for exposure time (one-, two-, and three-year treatments and ambient sediments) and the factor sampling year $(2003,2004,2005)$ independently of treatment were not significant. ANOSIM of the cosine similarity values, by contrast, showed clearly higher global $\mathrm{R}$ values. The grouping for exposure time showed that the different treatments and the ambient data are separated quite well. Additionally, the cosine similarity data of grouped samples from different sampling years are clearly dis-

\section{Table 4}

Results of ANOSIM for the Bray-Curtis and cosine similarity applied to meiofauna data from three different treatments and ambient control samples from Brandal, Kongsfjorden, Spitsbergen (*groups well separated; **groups clearly distinguishable)

\begin{tabular}{lccll}
\hline ANOSIM & & Bray Curtis & & Cosine \\
\cline { 1 - 1 } Test for factor grouping & & Global R & & Global R \\
\cline { 1 - 1 } Exposure time (1-, 2-, 3-year, and ambient) & & 0.37 & & $0.67^{*}$ \\
Sampling year (2003, 2004, 2005) & 0.46 & & $0.83^{* *}$ \\
1-year exposure 2003 vs 2004 & & -0.17 & 0.42 \\
1-year exposure 2004 vs 2-year exposure 2004 & 0.22 & \\
3-year exposure 2005 vs ambient samples 2005 & -0.03 & & 0.07 \\
\hline
\end{tabular}

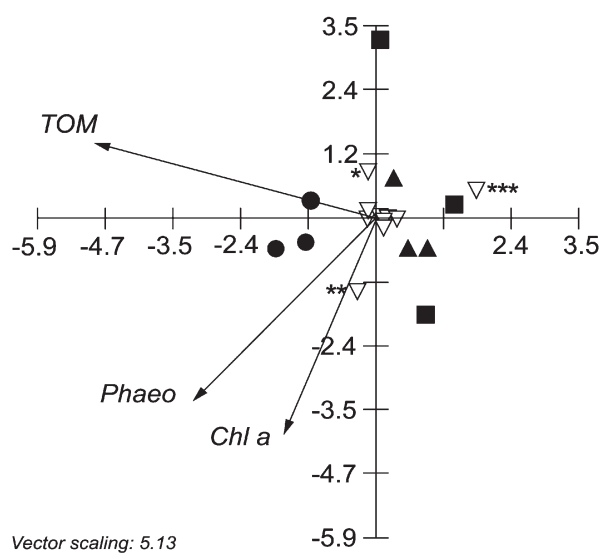

Fig. 4. Canonical correspondence analysis of samples from sediments exposed for one (black squares), two (black triangles) and three years (black dots), and meiofauna taxa (white triangles; *Cumacea, **Amphipoda, ***Rotifera) according to environmental data (vectors: total organic matter - TOM; chlorophyll a - Chla; phaeopigments - Phaeo).

tinguishable with global $\mathrm{R}=0.83$. Both similarity indices indicated that the grouping of samples by sampling year represents reality better than the grouping by exposure time.

Detailed analyses of part of the data groups show that there are no inter-annual differences in first-year primary succession between sediments exposed for one year from 2003 and 2004. Additionally, sediments exposed for one and two years collected in the same year (2004) do not show a group affiliation at all, nor is there any difference between the three-year and ambient samples from 2005.

\subsection{Canonical correspondence analysis}

A canonical correspondence analysis (CCA; Fig. 4) for 12 variables (meiofauna taxa) and 9 cases ( 3 replicates per treatment) was performed for the environmental data with 3 variables (total organic matter - TOM; chlorophyll a - Chla; phaeopigments - Phaeo). The ordination diagram of CCA displays samples and animal data as points and environmental variables as vectors (Fig. 4). The vector for TOM decreases with the first axis (x), whereas Chla and Phaeo decrease with the $y$ axis. For data interpretation the vectors can virtually be produced through the intersection of the axis. The ordination of data points in relation to environmental vectors is determined by projecting the data points at a right angle to the corresponding vector (Ter Braak, 1987).

The CCA shows that the longer the exposure time, the more organic matter and chlorophyll degradation products, as represented by the phaeopigments, are accumulated on the sediment. While the replicates from the one-year exposure deviate very significantly from each other, two- and three-year replicates are more homogeneous within their groups. The CCA indicates that there is no significant correlation of most of the animal taxa with any of the environmental factors, though the very rare Cumacea, Amphipoda and Rotifera seem to have habitat preferences that are distinct from most of the other taxa.

\section{Discussion}

\subsection{Meiofauna and sediment factors}

The individual densities of the meiofauna higher taxa found at the $20 \mathrm{~m}$ deep experimental site off Brandal are not in line with the abundances reported by the only previous meiofauna study on subtidal sites in Kongsfjorden by Kotwicki et al. (2004). Although the first $5 \mathrm{~cm}$ of the sediment were sampled in their study (Van Veen grab; three subsampled cores with $3.8 \mathrm{~cm}^{2}$ surface each unified as a single sample per station, no information on replicates and calculation 
of median or mean per station) as compared to our experiment where only the first $3 \mathrm{~cm}$ were analysed, they only recorded two stations with meiofauna densities above 1000 ind. $/ 10 \mathrm{~cm}^{2}$. Both stations are located in the part of the fjord defined as the "outer" region at $75 \mathrm{~m}$ and $265 \mathrm{~m}$ depth, respectively. All shallower stations and all stations from the "inner" part of the fjord do not exceed the numbers found off Brandal at a depth of $20 \mathrm{~m}$. Brandal is situated at the western boundary of the inner fjord, which according to their findings is very poor in meiofauna densities, and opposite Blomstrandoya island, from which they report comparably high abundances. The discrepancy found is most certainly due to the fact that Kotwicki et al. (2004) sampled from a depth of 44 to $350 \mathrm{~m}$ and their stations always showed a silt and clay content of at least $86 \%$. This is contrary to Brandal, where we found $80 \%$ fine and medium sand and only $20 \%$ silt and clay. Additionally, the different sampling techniques (Van Veen grab versus corers placed by scuba diver) might play a role. On the other hand, it is obvious from their data that the content of organic matter cannot play a crucial role in meiofauna abundances on a larger scale for Kongsfjorden. Our results support this in that the TOM in our case is only about a half to a third of their highest measurements. Therefore the contrasting densities of Brandal and the deeper regions are most certainly due to the differences in sediment grain size.

When comparing the meiofauna abundances encountered in Kongsfjorden and off Brandal to Antarctic polar shallow water softbottom areas, the special low-density situation of the Arctic sites becomes obvious: de Skowronski and de Corbisier (2002) report up to threefold higher total meiofauna abundances from King George Island (South Shetland Islands, Antarctica) and Veit-Köhler et al. (2008) even reported a maximum value of 16845 ind./ $10 \mathrm{~cm}^{2}$ for the same island (0 - $5 \mathrm{~cm}$ sediment depth). Vanhove et al. (2000) report very high but highly variable meiofauna densities from Signy Island (South Orkney Islands, Antarctica) from a monitoring site over a period of 19 months. Only Lee et al. (2001) encountered densities at the control sites of an iceberg scour time series that are comparable to our values.

The very high copepod relative abundances (20.3 - 34.6\%) within the experimental containers are exceptional for polar shallow areas even in the samples of the three-year treatment. In our experiment only the ambient sediments revealed relative abundances, e.g. 7.6\% for copepods, comparable to Kotwicki et al. (2004) who found values between 0 and 10\%. This supports our findings that the developing meiofaunal communities in our experiment are not similar to ambient values. The same is true for the Antarctic communities: de Skowronski and Corbisier (2002) found an average of only 9.5\% Copepoda in total meiofauna. Veit-Köhler et al. (2008) report copepod percentages that never exceeded $2.8 \%$ of the total soft-bottom meiofauna in 24 single core samples. The figures determined by Lee et al. (2001) with $2.3 \%$ copepods in their control samples are also comparably low.

Overall, we found high meiofauna densities at Brandal as compared to other sites in Kongsfjorden that can be explained only partly by food availability, but most certainly by water depth, sediment stability, sedimentation processes near the glacier (Kotwicki et al., 2004) and therefore sediment grain size. But as compared to Antarctic soft bottom shallow water sites, the densities found at Brandal are quite low. This is most probably due to differences in total organic matter, which at Brandal is low for polar shallow waters, i.e. $1.49 \%$ to $3.19 \%$ of the sediment dry mass.

\subsection{Colonisation and community development}

Colonisation of sediments by meiofauna is generally a rapid procedure. This has been shown in several studies (reviewed by Coull and Palmer, 1984), but the remaining question for the Arctic is whether the newly establishing communities are comparable to the naturally existing ones in the surrounding sediment.

Settlement itself is controlled by several processes and three major mechanisms have been identified: locomotion, dispersal by water currents and larval colonisation. The three methods act on different time scales (Peck et al., 1999).

While species with highly motile stages may invade the substrate actively, other groups depend on external forces like currents or recruitment via meroplanktic larvae. Colonisation by recruits in our case is unlikely as meiofauna taxa do not have planktonic larval stages. The observed increase in nematode abundance paralleled by a decrease in copepod abundance (Fig. 2) can thus be explained by the behaviour of the taxonomic groups: While the benthic Harpacticoida include several taxa capable of leaving the sediment and actively swimming small distances (Armonies, 2000; Thistle and Sedlacek, 2004), nematodes are exclusively infauna and mainly colonise sediments by active lateral migration (Schratzberger et al., 2004b). A laboratory experiment revealed that all specimens actively leaving the Brandal sediments when exposed to darkness were crustaceans (own unpublished data). Therefore, it must have been easier for actively swimming benthic copepods to surmount the container walls and settle inside. Adult sediment-dwelling copepods and nematodes may have colonised the sediment after resuspension and settlement events (Thistle et al., 1995; Schratzberger et al., 2004a) and then increased in abundance by reproduction.

Nematoda and Copepoda, the two most abundant taxa in meiofauna samples, are strongly correlated with food supply, among other environmental factors. Throughout our experiment food in terms of amount of organic matter and sedimented primary production accumulated in the sediment and likewise changed communities. Since the fluxes to the sediment may differ from year to year, the restart of the experiment in 2003 and the introduction of "sampling year" as a factor in our statistical analyses helped to interpret our findings.

While exposure time does not seem to be the most important factor for the state of the meiofauna assemblage, sampling year definitely is. However, the discrepancies detected by the similarity analyses using the different grouping factors "exposure time" versus "sampling year" did not contradict the idea of a temporally maturing meiofauna assemblage on a scale of years. A certain dependence of "exposure time" and "sampling year" in our data set was technically unavoidable. Nevertheless, we can affirm that the meiofauna assemblages of our experiment had reached a state closely related to ambient communities only after three years of exposure. The resemblance of three-year and ambient samples contrasts with observations on the establishment of macrozoobenthic communities within the same containers (Laudien and Sahade, unpubl. data) that did not reach the mature stage after three years of development. It has been shown that colonisation of settlement substrates by macrofauna in Antarctica is at least an order of magnitude slower than at temperate or tropical sites (Barnes, 1996; Stanwell-Smith and Barnes, 1997).

With regard to one-off studies our experiment underlines that generalisations from spatially or temporally single-spot samplings should be made cautiously and an appropriate number of replicates should be taken. Firstly, the sampled spots might not be representative for the whole area and secondly they might be in a transitional non-reproducible stage.

\subsection{Disturbances and recovery}

Kotwicki et al. (2004) discuss the influence of environmental disturbance on meiofauna communities in the inner Kongsfjorden. They find glacial runoff in terms of freshwater input and enhanced sedimentation rates to be one reason for low individual numbers. Obviously the Brandal experimental site does not fit into their scheme since it is as diverse and populated as their station 20 at a depth of $265 \mathrm{~m}$ in the outer bay. Although Brandal represents a very shallow depth not sampled by them $(20 \mathrm{~m})$, it is even more astonishing that melt water and glacial runoff should not negatively influence the meiofauna assemblages at this site. 
Polar shallow water systems are affected by environmental changes first and act as small-scale laboratories (Dayton, 1990). Iceberg scouring is likely to be one of the most common disturbances in those benthic habitats. In fact, Laudien et al. (2007) related macrobenthic community differences of the same habitat to scouring. The only existing study recording shallow water meiofauna recovery after iceberg impact stems from the Antarctic (Lee et al., 2001). The latter found the data difficult to interpret because a rapid return of the meiofauna after the impact was then followed by a decrease in abundances. As the distribution of our data indicates a high variability between replicates (Table 3 ), we can only again stress the importance of enhanced replicative sampling.

Meiofauna may be less sensitive to sediment disturbance and may react with a more rapid establishment of mature natural communities than macrofauna (Warwick et al., 1990), whose recovery requires many years (Picken, 1985). On the other hand, the lacking structuring effect of macrofauna in our case could be a reason for the skewed colonisation of the provided substrates by meiofauna since the macrofauna itself was far from reaching a stage comparable to the situation outside of the containers (Laudien and Sahade, unpubl. data).

Furthermore, it is clear that barriers like the container walls in our experiment hinder nematodes in their active lateral invasion of newly exposed areas. Schratzberger et al. (2004a, 2004b) showed that lateral migration takes time and does not necessarily culminate in the establishment of assemblages similar to the source communities. According to Chandler and Fleeger (1983), large-scale defaunation of meiobenthic communities recovers more slowly than small-scale disturbances. Nematode colonisation in our case was restricted to a passive water-borne process of dispersal, which would also be necessary for colonisation of larger areas.

Obviously even three years of exposure were scarcely enough to establish a community with relative abundances comparable to the ambient assemblage. This leads us to the assumption that the colonisation of large newly ice-free or defaunated areas by meiofauna, at least in arctic Kongsfjorden, does not occur on the same time scale as in temperate regions.

\section{Conclusions}

- Polar meiofauna communities show extremely long colonisation and recovery times. This is especially relevant for newly ice-free areas and defaunated zones in iceberg scours.

- Brandal represents the highest meiofauna densities at the local scale for inner Kongsfjorden, though compared to other polar shallow water soft sediments, the site is exceptional in its low total meiofauna abundances.

- The experiment revealed total meiofauna individual numbers comparable to ambient sediments after one year of exposure, but high copepod relative abundances characterised the colonising communities even after three years of exposure.

- In addition, the analyses of our data set stress the importance of replicative sampling and the use of adequate similarity indices.

\section{Acknowledgements}

We are grateful to the scientific diving group of the Alfred-WegenerInstitute for Polar and Marine Research (AWI) for assistance during the installation and sampling of the experimental set-up, especially Tilman Alpermann, Dr. Michael Assmann, Saskia Brandt, Marko Herrmann, Max Schwanitz, and Hendrik Wessels. Our thanks are due to Kjersti Dale for her help in the Marine Laboratory of Kingsbay AS, Bianca Wenzel and Alejandro Olariaga for support in sample treatment. RS is indebted to the German Academic Exchange Service (DAAD) for financing travel; AWI and IPEV provided working facilities at the AWIPEV platform (Spitsbergen). Four anonymous reviewers made comments, that improved the original manuscript considerably.

\section{References}

Armonies, W., 2000. A method for rapid abundance estimation of semiplanktonic meiofauna. Helgol. Mar. Res. 54, 213-223.

Arntz, W.E., 1981. Entwicklung von marinen Bodentiergemeinschaften unter Ausschluß von Räubern: nur Artefakte? Meeresforsch. 28, 189-204.

Barnes, D.K.A., 1996. Low levels of colonisation in Antarctica: the role of bryozoans in early community development. In: Gordon, D.P., Smith, A.M., Grant-Mackie, J.A. (Eds.), Bryozoans in space and time. Proc. 10 th Int. Bryozool. Conf. National Institute of Water \& Atmospheric Research Ltd, Wellington, New Zealand, pp. 19-28.

Barnes, D.K.A., 1999. The influence of ice on polar nearshore benthos. J. Mar. Biol. Assoc. UK 79, 401-407.

Barrie, J.V., 1980. Iceberg-seabed interaction (Northern Labrador Sea). Ann. Glaciol. 1 71-76.

Bluhm, B., Iken, K., Laudien, J., Lippert, H., 2001. German activity in cold water scientific diving. In: Jewett, S.C. (Ed.), Cold Water Diving for Science. Proceedings of the 21st Annual Scientific Diving Symposium, American Academy of Underwater Sciences: University of Alaska Sea Grant, AK-SG-01-06, Fairbanks, pp. 1-4.

Brunswig, D., Arntz, W.E., Rumohr, H., 1976. A tentative field experiment on population dynamics of macrobenthos in the western Baltic. Kieler Meeresforsch. Sonderh. 3 , 49-59.

Chandler, T.G., Fleeger, J.W., 1983. Meiofaunal colonization of azoic estuarine sediment in Louisiana: mechanisms of dispersal. J. exp. mar. Biol. Ecol. 69, 175-188.

Clarke, K.R., Gorley, R.N., 2006. PRIMER v6: User Manual/Tutorial. PRIMER-E: Plymouth.

Conlan, K.E., Lenihan, H.S., Kvitek, R.G., Oliver, J.S., 1998. Ice scour disturbance to benthic communities in the Canadian High Arctic. Mar. Ecol. Prog. Ser. 166, 1-16.

Conover, W.J., 1980. Practical nonparametric statistics, 2nd ed. Wiley, New York.

Cook, A.J., Fox, A.J., Vaughan, D.G., Ferrigno, J.G., 2005. Retreating glacier fronts on the Antarctic Peninsula over the past half-century. Science 308, 541-544.

Coull, B.C., Palmer, M.A., 1984. Field experimentation in meiofaunal ecology. Hydrobiologia 118, 1-19.

Dayton, P.K., 1990. Polar benthos. In: Smith, W.E. (Ed.), Polar Oceanography, part B: Chemistry, Biology and Geology. Academic Press, London, pp. 631-685.

Dayton, P.K., Mordida, B.J., Bacon, F., 1994. Polar marine communities. Amer. Zool. 34 90-99.

Dowdeswell, J.A., Forsberg, C.F., 1992. The size and frequency of icebergs and bergy bits derived from tidewater glaciers in Kongsfjorden, Northwest Spitsbergen. Polar Res. $11,81-91$.

Foster, M.S., 1975. Regulation of algal community development in a Macrocystis pyrifera forest. Mar. Biol. 32, 331-342.

Gutt, J., Piepenburg, D., 2003. Scale-dependent impacts of catastrophic disturbances by grounding icebergs on the diversity of Antarctic benthos. Mar. Ecol. Prog. Ser. 253, 77-83.

Gutt, J., Starmans, A., Dieckmann, G., 1996. Impact of iceberg scouring on polar benthic habitats. Mar. Ecol. Prog. Ser. 137, 311-316.

Hammer, Ø., Harper, D.A.T., Ryan, P.D., 2001. PAST: Paleontological Statistics Software Package for Education and Data Analysis. Palaeontol. Electronica 4 (1), 9 p.

Hop, H., Pearson, T., Hegseth, E.N., Kovacs, K.M., Wiencke, C., Kwasniewski, S., Eiane, K., Mehlum, F., Gulliksen, B., Wlodarska-Kowalczuk, M., Lydersen, C., Weslawski, J.M., Cochrane, S., Gabrielsen, G.W., Leakey, R.J.G., Lønne, O.J., Zajaczkowski, M., FalkPetersen, S., Kendall, M., Wängberg, S.-A., Bischof, K., Voronkov, A.Y., Kovaltchouk, N.A., Wiktor, J., Poltermann, M., di Prisco, G., Papucci, C., Gerland, S., 2002. The marine ecosystem of Kongsfjorden, Svalbard. Polar Res. 21 (1), 167-208.

Jørgensen, L.L., Gulliksen, B., 2001. Rocky bottom fauna in arctic Kongsfjord (Svalbard) studied by means of suction sampling and photography. Polar Biol. 24, 113-121.

Kotwicki, L., Szymelfenig, M., De Troch, M., Zajaczkowski, M., 2004. Distribution of meiofauna in Kongsfjorden, Spitsbergen. Polar Biol. 27, 661-669.

Laudien, J., Herrmann, M., Arntz, W.E., 2007. Soft-bottom species richness and diversity as a function of depth and iceberg scour in Arctic glacial Kongsfjorden (Svalbard) Polar Biol. 30, 1035-1046.

Lee, H.J., Vanhove, S., Peck, L.S., Vincx, M., 2001. Recolonisation of meiofauna after catastrophic iceberg scouring in shallow Antarctic sediments. Polar Biol. 24, 918-925.

Lippert, H., Iken, K., Rachor, E., Wiencke, C., 2001. Macrofauna associated with macroalgae in the Kongsfjord (Spitsbergen). Polar Biol. 24, 512-522.

McIntyre, A.D., Warwick, R.M., 1984. Meiofauna techniques, In: Holme, N.A., McIntyre, A.D. (Eds.), Methods for the study of marine benthos, 2nd ed. Blackwell, pp. 217-244.

Peck, L.S., Brockington, S., Vanhove, S., Beghyn, M., 1999. Community recovery following catastrophic iceberg impacts in a soft-sediment shallow-water site at Signy Island, Antarctica. Mar. Ecol. Prog. Ser. 186, 1-8.

Pfeifer, D., Bäumer, H.-P., Dekker, R., Schleier, U., 1998. Statistical tools for monitoring benthic communities. Senckenbergiana marit. 29 (1/6), 63-76.

Picken, G.B., 1985. Marine habitats - benthos. In: Bonner, W.N., Walton, D.W.H. (Eds.), Key environments, Antarctica, Chap 3. Pergamon Press, Oxford, pp. 154-172.

Rumohr, H., Arntz, W.E., 1982. The "Benthosgarten" - a new approach for the study of soft bottom communities. Meeresforsch. 29, 225-238.

Sachs, L., 1993. Statistische Methoden, 7th ed. Springer-Verlag, Berlin, 312 p.

Sarnthein, M., Richter, W., 1974. Submarine experiments on benthic colonization of sediments in the western Baltic Sea. I. Technical Layout. Mar. Biol. 28, 159-164.

Schratzberger, M., Dinmore, T.A., Jennings, S., 2002. Impacts of trawling on the diversity, biomass and structure of meiofauna assemblages. Mar. Biol. 140, 83-93.

Schratzberger, M., Bolam, S.G., Whomersley, P., Warr, K., Rees, H.L., 2004a. Development of a meiobenthic nematode community following the intertidal placement of various types of sediment. J. Exp. Mar. Biol. Ecol. 303, 79-96.

Schratzberger, M., Whomersley, P., Warr, K., Bolam, S.G., Rees, H.L., 2004b. Colonisation of various types of sediment by estuarine nematodes via lateral infaunal migation: a laboratory study. Mar. Biol. 145, 69-78. 
de Skowronski, R.S.P., Corbisier, T.N., 2002. Meiofauna distribution in Martel Inlet, King George Island (Antarctica): sediment features versus food availability. Polar Biol. 25, 126-134.

Stanwell-Smith, D., Barnes, D.K.A., 1997. Benthic community development in Antarctica: Recruitment and growth on settlement panels at Signy Island. J. Exp. Mar. Biol. Ecol. 212, 61-79.

Svendsen, H., Beszczynska-Møller, A., Hagen, J.O., Lefauconnier, B., Tverberg, V., Gerland, S., Ørbæk, J.B., Bischof, K, Papucci, C., Zajaczkowski, M., Azzolini, R, Bruland, O. Wiencke, C., Winther, J.-G., Dallmann, W., 2002. The physical environment of Kongsfjorden-Krossfjorden, an Arctic fjord system in Svalbard. Polar Res. 21 (1), 133-166.

Ter Braak, C.J.F., 1986. Canonical correspondence analysis: A new eigenvector technique for multivariate direct gradient analysis. Ecology 67 (5), 1167-1179.

Ter Braak, C.J.F., 1987. The analysis of vegetation-environment relationships by canonical correspondence analysis. Vegetatio 69, 69-77.

Thistle, D., Sedlacek, L., 2004. Emergent and non-emergent species of harpacticoid copepods can be recognized morphologically. Mar. Ecol. Prog. Ser. 266, 195-200.

Thistle, D., Weatherly, G.L., Wonnacott, A., Ertman, S.C., 1995. Suspension by winter storms has an energetic cost for adult male benthic harpacticoid copepods at a shelf site. Mar. Ecol. Prog. Ser. 125, 77-86.
Vanhove, S., Beghyn, M., Van Gansbeke, D., Bullough, L.W., Vincx, M., 2000. A seasonally varying biotope at Signy Island, Antarctic: implications for meiofaunal structure. Mar. Ecol. Prog. Ser. 202, 13-25.

Veit-Köhler, G., Laudien, J., Knott, J., Sahade, R., 2006. Meiobenthic assemblages colonizing artificial soft sediments at $20 \mathrm{~m}$ depth in Arctic glacial Kongsfjorden, Spitsbergen, Svalbard. doi.pangaea.de/10.1594/PANGAEA.552218.

Veit-Köhler, G., Antacli, J.C., Rose, A., 2008. Metazoan meiofauna in Potter Cove, King George Island. In: Wiencke, C., Ferreyra, G.A., Abele, D., Marenssi, S. (Eds.), The Antarctic ecosystem of Potter Cove, King-George Island (Isla 25 de Mayo). Ber. Polarforsch. Meeresforsch., 571, pp. 135-140.

Warwick, R.M., Platt, H.M., Clarke, K.R., Agard, J., Gobin, J., 1990. Analysis of macrobenthic and meiobenthic community structure in relation to pollution and disturbance in Hamilton Harbour, Bermuda. J. Exp. Mar. Biol. Ecol. 138, 119-142.

Whittington, R.J., Forsberg, C.F., Dowdeswell, J.A., 1997. Seismic and side-scan sonar investigations of recent sedimentation in an ice-proximal glacimarine settino, Kongsfjorden, north-west Spitzbergen. In: Davies, T.A. (Ed.), Glaciated continental margins - an atlas of acoustic images. Chapman and Hall, pp. 175-178.

Wlodarska-Kowalczuk, M., Pearson, T.H., 2004. Soft-bottom macrobenthic faunal associations and factors affecting species distributions in an Arctic glacial fjord (Kongsfjord, Spitsbergen). Polar Biol. 27, 155-167. 